\title{
The Calculation of Chinese Short-Term International Capital Flow: Based on BOP
}

\author{
Gang Shi ${ }^{1} \&$ Zee Lian ${ }^{1}$ \\ ${ }^{1}$ Institute of National Accounts, Beijing Normal University, Beijing, China \\ Correspondence: Gang Shi, Institute of National Accounts, Beijing Normal University, Beijing, No. 19 \\ Xinjiekouwai St., China. Tel: 86-139-1113-5949. E-mail: shigang@bnu.edu.cn
}

Received: May 16, 2014

Accepted: May 26, 2014

Online Published: July 25, 2014

doi:10.5539/ijef.v6n8p103

URL: http://dx.doi.org/10.5539/ijef.v6n8p103

\begin{abstract}
Short-term international capital flows are generally considered to have strong volatility, strong current scale changes, and easy flow direction reversal. Thus short-term international capital flows usually exert a negative influence on a country's real economy and the financial markets, and can produce financial crises. This article briefly examines the channels of short-term international capital flows through a comparative analysis of different methods for estimating the short-term capital flows based on the Chinese Balance of International Payments (BOP), and theoretically demonstrates the relationship between direct and indirect methods. China's short-term international capital flows are subsequently calculated based on the indirect method and the improved direct method. Finally, the paper tests the estimated results, and provides conclusions and recommendations.
\end{abstract}

Keywords: improved indirect method, improved direct method, BOP, short-term capital

\section{Introduction}

Short-term international capital flows are generally considered to have strong volatility, strong current scale changes, and easy flow direction reversal, thus negatively influencing a country's real economy and financial markets (Zhang, 2011). Various international financial crises that occurred in the 1990s indicate that short-term international capital flows are closely related to the outbreak of those crises. Today, China's economy is more open, capital projects are gradually opening up, and the channels and means of international short-term capital in China are becoming increasingly diverse. These factors not only create difficulties for Chinese regulatory authorities, but also bring challenges to China's economic development and the stability of its financial markets. Therefore, conducting estimates of short-term international capital flows is important.

This article will estimate the scale of short-term international capital flows based on a comparative analysis of the definition of short-term international capital flows. The structure of this article is as follows: Section 2 reviews the definition and estimations of short-term capital flows in the literature. Section 3 theoretically demonstrates the relationship between the direct method and indirect method based on the analysis of short-term capital flow channels. Section 3 also estimates China's short-term capital flows by using the improved residual method and the improved direct method. Section 4 raises the test standards for the estimation results and evaluates the results of China's short-term international capital flows estimation. Section 5 gives the related conclusion and recommendation.

\section{Literature Summary}

\subsection{Review of the Definition of Short-Term International Capital Flow}

Various scholars have their own views about the definition of short-term international capital flow. As seen in the literature, we can define short-term international capital flow from the four following aspects.

First, we can divide capital flows into short-term international capital flows and long-term international capital flows according to time. In its fore four editions of the Balance of Payments Manual, the International Monetary Fund (IMF) defines lending or investment with a period of less than one year as short-term capital (including short-term securities investments, loans, inflation-proof capital flows, speculative capital flows and trade financing), and lending or investment with a period of more than one year as long-term capital (including direct investment, securities investment over a period of more than one year, and international loans). Claessens (1993) and Rodrik and Velasco (1999) also follow this definition. With the development of financial markets and the 
innovation of financial instruments, medium- and long-term capital (particularly stocks, bonds and other securitized assets,) have become important forms of short-term international capital flows. If the remaining maturity of long-term capital is less than one year, there is essentially no difference between this kind long-term capital and short-term capital. And the importance of dividing long-term capital and short-term capital according to the length of the period has been weakened. Based on this weakened importance, the IMF (1993) emphasized in its fifth edition of the Balance of Payments Manual that the division of short-term and long-term assets and liabilities in accordance with the contract period of more than one year or less than one year, was only applied to the fixed period's other investments (including trade credits, loans, currency and deposits, and a variety of receivables and payables).

Second, we can divide capital flows into short-term international capital flows and long-term international capital flows according to investment and speculation (Kindleberger, 1985; Chuban, Perez-Quiros and Poper, 1996; Song Wenbing, 1999; the capital flow's vulnerability analysis and early warning system Task Force of the State Administration of Foreign Exchange, 2005). Generally speaking, speculative "hot money" is considered to be a short-term capital flow, although Tang Xu and Liang Meng (2007) and Zhang Ming (2008) believe that there are also long-term speculative capital flows in "hot money". But the capital for investment contain both short-term capital flows such as trade capital flows, financial capital flows, and long-term capital flows such as direct investment. In reality, there are no clear boundaries between investment and speculation, making it difficult to distinguish investment capital and speculative capital flows within international capital flows, which not only causes problems for statistical analysis, but also makes the actual operation difficult.

Thirdly, we can divide the short-term and long-term capital flows according to illegality and legality (Bhagwati, 1964; Bhagwati, Krueger, \& Wibulswasdi, 1974; Wang, 2010). After analyzing these criteria, Benu Schneider (2003) concluded that illegal capital flows are mainly reflected in the misinvoicing import and export of foreign trade, and that they should generally be regarded as short-term capital flows. For a definition of this approach, we note two points: (a) in addition to the misinvoicing import and export, there are other illegal capital flow channels that are difficult to calculate, such as the use of "underground banks" for capital transfers; (b) illegal capital flows are just one part of short-term capital flows, and a considerable proportion of short-term capital flows are also made through investments in securities and other legal investment channels.

Fourthly, we can distinguish short-term and long-term capital flow according to liquidity. Li Chong (2003) considers capital (based on the flow strength of transnational capital) in which liquidity is weak as short-term capital and capital in which liquidity is strong as long-term capital. Qu Fengjie (2006) and Liu Renwu, Qin Daoai and Liu Hua (2008) posit that the risk of short-term capital flows is that a sudden change in direction may threaten macroeconomic stability. Thus, Qu Fengjie (2006) and Liu Renwu, Qin Daoai and Liu Hua (2008) define international short-term capital as capital flow that has a loan period of less than one year or may change the flow direction at any time. Based on liquidity, the definition not only considers the time period of the capital flow, but also the fact that its flow direction change at any time, which renders long-term capital with a long investment period that is about to expire into short-term capital. Compared to the previous three definitions, this definition has better applicability.

We must note that in addition to sudden changes in flow direction, if the "risk" exerts real influence on macroeconomics, it must require a large amount of short-term capital, which means we need to highlight the concept of the "quantity" of short-term capital flows. Therefore, the definition of short-term capital flow in this paper will reference the research of Qu Fengjie (2006) and Liu Renwu, Qin Daoai and Liu Hua (2008), and emphasize the concept of "quantity" of short-term capital flows.

\subsection{Comments on the Calculation Method for Short-Term International Capital Flows}

Due to the various definitions of short-term international capital flow, the calculation methods of short-term international capital flows are also different. Many scholars have their own views on the classification of the calculation methods of short-term international capital flows. Benu Schneider (2003) divides the calculation method of short-term capital flows into three types based on the various definitions of short-term capital flow, which are the generalized calculation method, the Dooley method and the illegal capital flow calculation method. Liu Renwu, Qin Daoai and Liu Hua (2008) divides the calculation method of short-term capital flows into five types: the indirect net investment adjustment method based on the net errors and omissions item, the indirect net investment adjustment method based on the partial adjustment, the direct method (also known as the Cuddington method), the indirect method (also known as residual method) and the Cline method. Zhang Ming (2011) concluded that there are three types of calculation methods for short-term capital flow, the direct method, the indirect method and the hybrid method (also known as Dooley method). Yasemin and Talha (2012) divide the 
calculation method for short-term capital flows into four types: the direct method, the indirect method, the hybrid method and the trade misinvoicing method.

In fact, Schneider's (2003) generalized calculation method includes the indirect method and the direct method. The two types of indirect net investment adjustment methods mentioned by Liu Renwu, Qin Daoai and Liu Hua (2008) can be considered as two variants of the direct method, and the Cline method can be considered as a modification of the indirect method. The illegal capital flows calculation method raised by Schneider (2003) is actually the same as the trade misinvoicing method raised by Yasemin and Talha (2012). The illegal capital flows calculation method only estimates the illegal portion of short-term international capital flows, and is incapable of measuring all of the short-term international capital flows. In addition, due to the sensitivity of the level and structure of interest rates, the compiling investment income reporting procedures, and other factors, there is a large degree of measurement error in the Dooley method. Thus, the Dooley method is rarely used (Schneider, 2003). Therefore, the following part of this section will comment mainly on indirect and direct method.

The direct method was first proposed by Cuddington (1986). This method principally considers the net errors and omissions in the BOP table as a basic item that reflects short-term international capital flows, and then joins other items of the BOP, which may contain short-term international capital flows, and calculate short-term international capital flows. Little research uses the direct method to calculate short-term international capital flows compared to the indirect method. A comparative analysis of the calculation indicators, the calculation formula and the literature on the direct method are shown in Table 1. As seen from Table 1, there are approximately 11 calculation formulas for the direct method, which are all based on the net errors and omissions item or its adjustments as well as adding other relative indicators. Second, among the adding indicators, the trade misinvoicing amount, the short-term investment item and other short-term capital items of other sectors are used most. Third, there are, mainly, two types of adjustment methods for adjusting the indicators. One method adjusts the indicators based on an empirical analysis for estimating an adjustment coefficient; the other method adjusts the indicators based on their variety of means.

Table 1. Indicators, calculation forum and literature review regarding direct methods

\begin{tabular}{|c|c|}
\hline Indicators & Literature \\
\hline Net errors and omissions (A) & Most literature of direct method \\
\hline Adjustment of A (AT1): A items accounted for the proportion of total trade & Ren Hui (2001) \\
\hline in developed countries & Liu Renwu, Qin Daoai and Liu Hua (2008), Wang Xin \\
\hline Adjustment of A (AT2): $40 \%$ of A items & $(2005)$ \\
\hline \multicolumn{2}{|l|}{ Current account balance (C) } \\
\hline \multicolumn{2}{|l|}{ Trade surplus (C1) } \\
\hline Adjustment of $\mathrm{C} 1$ (C1T1): The actual value minus moving average & Liu Liya (2008) \\
\hline Import and Export false reporting amount (C2) & Yang Haizhen and Chen Jinxian (2000), Ren Hui (2001), \\
\hline Adjustment of $\mathrm{C} 2(\mathrm{C} 2 \mathrm{~T})$ : Total import and export volume multiplied by a & Lan Zhenhua and Chen Lin (2008), Zhang Ming (2011), \\
\hline coefficient $(1 \%)$ to adjust & Liu Renwu, Qin Daoai and Liu Hua (2008) \\
\hline \multicolumn{2}{|l|}{ Income differences (C3) } \\
\hline $\begin{array}{l}\text { Adjustment of } \mathrm{C} 3(\mathrm{C} 3 \mathrm{~T}) \text { : The actual value minus the previous five-year } \\
\text { profit equilibrium value }\end{array}$ & Yin Yuming and Tao Haibo (2005) \\
\hline \multicolumn{2}{|l|}{ Current transfers differences $(\mathrm{C} 4)$} \\
\hline Adjustment of $\mathrm{C} 4$ (C4T1): The actual value minus the moving average & Liu Liya (2008) \\
\hline \multicolumn{2}{|l|}{ Adjustment of $\mathrm{C} 4$ (C4T2): The actual value multiplied by a factor (40\%) to } \\
\hline adjust & Liu Renwu, Qin Daoai and Liu Hua (2008) \\
\hline Capital and financial account balance (D) & Liu Renwu, Qin Daoai and Liu Hua (2008) \\
\hline Direct investment difference (D1) & Liu Renwu, Qin Daoai and Liu Hua (2008) \\
\hline \multicolumn{2}{|l|}{ Foreign direct investment difference (D11) } \\
\hline Adjustment of D11 (D11T1): The actual value minus the model predictions & Yin Yuming and Tao Haibo (2005) \\
\hline \multicolumn{2}{|l|}{ Adjustment of D11 (D11T2): Estimate a proportion (30\%) to adjust } \\
\hline & Liu Renwu and Tao Haibo (2008) \\
\hline $\begin{array}{l}\text { Investments in securities balance (including equity securities and debt } \\
\text { securities) (D2) }\end{array}$ & Kant (1996) \\
\hline $\begin{array}{l}\text { Short-term project in investment items under financial account (including } \\
\text { short-term trade credit, short-term loans, currency and deposits, other }\end{array}$ & \\
\hline
\end{tabular}


short-term assets) (D3)

Adjustment of D3 (D3T): The actual value minus the exponential Yin Yuming and Tao Haibo (2005)

smoothing predictive value

Short-term investment items under financial account (including money

market instruments, short-term trade credit, short-term loans, currency and

deposits, other short-term assets) (D31)

Trade credit Item D32

Adjustment of D32 (D32T): The actual value minus the processing and normal trade credit

Other capital item in other departments D33

Other short-term capital item in other departments D34

Qu Fengjie (2006), Lan Zhenhua and Chen Lin (2008), Zhang Ming (2011)

Yang Haizhen and Chen Jinxian (2000), Ren Hui (2001)

Yang Haizhen and Chen Jinxian (2000)

Cuddington (1986), Kant (1996), Yang Shenggang and

Liu Zhonghua (2000), Xiu Jing and Zhang Ming (2002),

Yin Yuming, and Tao Haibo (2005)

Calculation forum by direct method (short-term capital flow: SCF1)

1. SCF1= A+D34; Cuddington (1986), Kant (1996), Yang Shenggang and Liu Zhonghua (2000), Xiu Jing and Zhang Ming (2002). 2. $\mathrm{SCF} 1=\mathrm{A}+\mathrm{D} 34+\mathrm{D} 2$; Kant (1996). 3. SCF1= A+D32+D33+C2; Yang Haizhen and Chen Jinxian (2000). 4. SCF1= AT1+D32T $+\mathrm{C} 2$; Ren Hui (2001). 5. SCF1= A+D34+C3T+D11T1+D3T; Yin Yuming and Tao Haibo (2005). 6. SCF1= A+D31; Qu Fengjie (2006). 7. SCF1= A+D31+C2; Lan Zhenhua, and Chen Lin (2008). 8. SCF1= A+C1T1+C4T1; Liu Liya (2008). 9. SCF1= AT2+D-D1; Liu Renwu, Qin Daoai and Liu Hua (2008). 10. SCF1= A+C2T+C4T2+D11T2; Liu Renwu, Qin Daoai and Liu Hua (2008). 11. A+D31+C2; Zhang Ming (2011).

Note. This table is created by the author according to the relative literature.

In summarizing the literature on the direct method, we find three common characteristics. First, all of the types of direct method are based on Cuddington's (1986) method, and the relationship between the direct method and the indirect method is not considered theoretically. Second, all of the direct method types are likely to underestimate actual short-term international capital flows. Zhang Ming (2011) claims that his direct method type has the widest caliber algorithm, but this claim is debatable. We believe that determining the width of the caliber of the direct algorithm does not lie in how many items are added, but in the comprehensiveness of analyzing the possible existing flow forms of short-term international capital. Third, all of the direct method types just produce simple analyses and no one has proposed test methods and standards for the calculating results.

The indirect method, also known as the residual method, was first proffered by the World Bank (1985). This method takes the following two terms, i.e., the external debt increases and the foreign direct investment net inflow as a state's sources of funding, and the other two terms, i.e., the official reserves increases and the current account deficit as the state's expenditures of funding. Then the scale of short-term capital flows can be calculated from the difference between the above two kinds of funding. More research has used the indirect method to measure short-term capital flows due to two disadvantages of the direct method. The first disadvantage is that the basic item used in the direct method, such as the net errors and omissions (a balancing item) may be caused by the hidden nature of short-term capital flows, or by statistical errors. The second disadvantage of the direct method is that it assumes that the item outside of its computing formula does not contain short-term capital flows, which can easily lead to an underestimation of the calculated results.

A comparative analysis of the calculation indicators, the calculation formula and the corresponding literature on the direct method are shown in Table 2. Table 2 shows that firstly there are about 20 types of calculation formulas for the indirect method, which are all based on the foreign exchange reserves increment or its adjustment term. Second, among all of the added indicators, the current account balance, the trade surplus, foreign direct investment, and external debt increases are used the most in the direct method. Third, the adjustment method used to adjust the indicators in the direct method is based on the adjustment coefficient which is estimated by the empirical analysis. 
Table 2. Indicators, calculation forum and literature review on indirect methods

\begin{tabular}{ll}
\hline Indicators & Literature \\
\hline Increment in foreign exchange reserves (B) & World Bank (1985) \\
$\begin{array}{l}\text { Adjustment of B (BT1): Use increment of the RMB } \\
\text { counterpart of foreign exchange reserves instead }\end{array}$ & Huiyong (2011) \\
$\begin{array}{l}\text { Adjustment of B (BT2): Use increment of foreign } \\
\text { exchange assets of the monetary authorities instead }\end{array}$ & \\
$\begin{array}{l}\text { Adjustment of B (BT3): Changes in the value of } \\
\text { reserve assets, excluding exchange rate variations }\end{array}$ & \\
$\begin{array}{l}\text { Adjustment of B (BT4): Changes in the value of } \\
\text { reserve assets, which exclude exchange rate variations, }\end{array}$ & \\
\begin{tabular}{l} 
coupled with the central bank CIC transfer to adjust \\
\hline
\end{tabular}
\end{tabular}

Current account balance (C)

Trade surplus $(\mathrm{C} 1)$

Adjustment of C1 (C1T2): Use goods and services trade surplus to adjust

Adjustment of $\mathrm{C} 1$ (C1T3): Exports multiplied by a ratio to adjust

Adjustment of C1 (C1T4): Minus capital flow hidden in trade surplus

Adjustment of C1 (C1T5): Use trade surplus of the previous 4 years instead

Adjustment of C1 (C1T6): Minus foreign speculative

capital inflow in trade accounts

Tourism balances (C11)

Import and export false reporting amount (C2)

Investment income balances (C31)

Workers compensation balances (C32)

Overseas investment income (C33)

Current transfers balances (C4)

Government departments current transfers (C41)

Direct investment balance (D1)
World Bank (1985), Morgan Guaranty Trust Company (1986), Cline (1987), Song Wenbin (1999), Yang Haizhen and Chen Jinxian (2000), Li Xiaofeng (2000), Yang Shenggang and Liu Zhonghua (2000), Xiu Jing and Zhang Ming (2002), Schneider (2003), Chen Xuebin, Yu Chenjun and Sun Jingfang (2007), Yu Shanpin and Zhang Wenxi (2008), Liu Renwu, Qin Daoai and Liu Hua. (2008), Yan Qifa (2010), Yasemin and Talha (2012)

International Statistical Information Center of the National Bureau of Statistics (2006), Wang Shihua and He Fan (2007), Michaelson (2010), Xu Gao (2007), Liu Liya (2008), Zhang Bin (2010), State Administration of Foreign Exchange (2011)

Feng Cai (2008), Zhang Ming(2011)

Lin Songli (2010)

Zhang Ming (2008), Zhang Ming and Xu Yisheng (2008)

Zhang Yihao and Shen Xiaohua (2008)

Li Huiyong (2011)

Cline (1987), Liu Renwu, Qin Daoai and Liu Hua (2008)

Song Wenbin (1999), Yang Haizhen and Chen Jinxian (2000), Li Xiaofeng (2000), Yan Qifa(2010), Zhang Ming(2011)

Cline (1987), Liu Renwu, Qin Daoai and Liu Hua (2008)

Zhang Ming (2011)

State Administration of Foreign Exchange (2011), Li Huiyong (2011)

Li Huiyong (2011)

Zhang Ming (2011)

World Bank (1985), Morgan Guaranty Trust Company (1986), Cline (1987), Song Wenbin (1999), Yang Haizhen and Chen Jinxian (2000), Li Xiaofeng (2000), Yang Shenggang and Liu Zhonghua (2000), Xiu Jing and Zhang Ming (2002), Schneider (2003), International Statistical Information Center of the National Bureau of Statistics (2006), Wang Shihua and He Fan (2007), Michaelson (2010), Chen Xuebin, Yu Chenjun and Sun Jingfang (2007), Yu Shanpin and Zhang Wenxi (2008), Xu Gao (2007), Zhang Yihao and Shen Xiaohua (2008), Feng Cai (2008), Liu Renwu, Qin Daoai and Liu Hua (2008), Liu Liya (2008), Lin Songli (2010), Zhang Bin (2010), Yan Qifa (2010), Zhang Ming (2011), State Administration of Foreign Exchange (2011), Yasemin and Talha (2012)

Adjustment of D1 (D1T1): The actual value minus capital flows hidden in FDI

Zhang Ming (2008), Zhang Ming and Xu Yisheng (2008)

Li Huiyong (2011)

Adjustment of D1 (D1T2): Monetary part of FDI minus speculative part of FDI and Chinese foreign direct investment 


Foreign direct investment balance (D11)
China's direct investment balance abroad (D12)
Foreign securities investment in the Chinese market
(Equity securities liabilities) (D21)
Overseas securities investment increment (D22)
The debenture capital inflows (D23)
Foreign equity and long-term bond investments (D24)
Short-term investments in financial accounts
(including money market instruments, short-term trade
credit, short-term loans, currency and deposits, other
short-term assets) (D31)
Trade credit item (D32)
Increment of net foreign assets of commercial banks
(D35)
The external loans increment(D36)
Net inflow of foreign other investment (D37)
Net outflow of foreign other investment (D38)
Other long-term foreign investment (D39)
The external debt incremental (stocks) (D40)

Adjustment of D40 (D40T): Use of external debt incremental flows instead

Short-term debt increment (D41)

Adjustment of D41(D41T): The actual value minus the speculative part of the increase in the short-term debt

Normal non-banking sector capital outflows (capital Yan Qifa (2010)

account balance) (D5)

Song Wenbin (1999)

Li Xiaofeng (2000)

Zhang Ming (2011)

Li Huiyong (2011)

\author{
Zhang Ming (2011) \\ Song Wenbin (1999), Li Xiaofeng (2000) \\ Song Wenbin (1999), Yang Haizhen and Chen Jinxian (2000), Li Xiaofeng \\ (2000) \\ Song Wenbin (1999), Li Xiaofeng (2000), Zhang Ming (2011), State \\ Administration of Foreign Exchange (2011), Li Huiyong (2011) \\ Yang Haizhen and Chen Jinxian (2000) \\ Zhang Ming (2011) \\ Liu Renwu, Qin Daoai and Liu Hua (2008)
}

Song Wenbin (1999, Yang Haizhen and Chen Jinxian (2000)

Morgan Guaranty Trust Company (1986), Cline(1987), Song Wenbin (1999),

Yang Haizhen and Chen Jinxian (2000), Yan Qifa (2010)

Li Xiaofeng (2000), Zhang Ming (2011)

World Bank (1985), Morgan Guaranty Trust Company (1986), Cline (1987), Song Wenbin (1999), Yang Haizhen and Chen Jinxian (2000), Li Xiaofeng (2000), Xu Gao (2007), Liu Renwu, Qin Daoai and Liu Hua (2008)

Yang Shenggang and Liu Zhonghua (2000), Xiu Jing and Zhang Ming (2002), Schneider (2003), Yan Qifa (2010), Yasemin and Talha (2012)

Calculation forum by indirect method (short-term capital flow: SCF2)

1. SCF2=B-C-D1-D4; World Bank (1985). 2. SCF2=B-C-D1-D4+D35; Morgan Guaranty Trust Company (1986). 3. SCF2=B- C- D1-D4+ D35+ C31+ C11; Cline (1987). 4. SCF2= B-C- D1-D4- D23- D21+D35+D32-C2; Yang Haizhen and Chen Jinxian (2000). 5. SCF2= B-CD1-D4- D21-D37+D12+D22+D38-C2; Li Xiaofeng (2000). 6. SCF2= B-C- D1-D4T; Yang Shenggang and Liu Zhonghua (2000), Xiu Jing and Zhang Ming (2002), Schneider (2003), Yasemin and Talha (2012). 7. SCF2=B-C1; Xie Guozhong (2005). 8. SCF2 =B-D1-C1; International Statistical Information Center of the National Bureau of Statistics (2006), Wang Shihua and He Fan (2007), Michaelson (2010). 9. SCF2 =B-D1-C; Chen Xuebin, Yu Chenjun and Sun Jingfang (2007), Yu Shanpin and Zhang Wenxi (2008). 10. SCF2=BT3-D1-C1-D4; Xu Gao (2007). 11. SCF2=B-D1-C1T5; Zhang Yihao and Shen Xiaohua (2008). 12. SCF2=B-D1-C1T2; Feng Cai (2008). 13. SCF2 =B-D1-C-D4+D31; Liu Renwu, Qin Daoai and Liu Hua (2008). 14. SCF2=B-C-D1-D4+C11+C31; Liu Renwu, Qin Daoai and Liu Hua (2008). 15. SCF2= BT1-D1-C1; Liu Liya (2008). 16. SCF2=BT3-D1T1-C1T4; Zhang Ming (2008). 17. SCF2=BT4D1T1-C1T4; Zhang Ming and Xu Yisheng (2008). 18. SCF2=BT1 -D1-C1T3; Lin Songli(2010). 19. SCF2= BT2 -D1-C1; Zhang Bin (2010). 20. SCF2=BT1-C-D1-D4T+D35+D5-C2; Yan Qifa (2010). 21. SCF2= BT1-C1T2-C32-C41-D1-D24-D39+D11+D22+D38+C2; Zhang Ming (2011). 22. SCF2=B-D1-C1-C33-D22; State Administration of Foreign Exchange (2011). 23. SCF2 =BT1-C1T6-D1T2-D41T-C33-C4-D22; Li Huiyong (2011).

Note. This table was derived by the author according to the relevant literature.

In summarizing the research on the indirect method, we find three characteristics common to the indirect method types. First, all of the types are based on an algorithm proffered by the World Bank (1985), and no theoretical analysis of the relationship between the indirect method and the direct method exists. Second, all of the research on the indirect method take into consideration that the direct method underestimates the scale of short-term international capital flows, while the indirect method overestimate the scale of short-term international capital flows. Compared to the direct method, the indirect method produces relatively accurate results. Third, there are no corresponding test methods and standards for the estimation results.

Notably, there is a class of literature that estimates short-term international capital flows using the direct and indirect methods independently, and considers the simple weighted average of these different results as the final calculating results. For example, Qu Fengjie (2006) and Chen Jinmei and Xu Zhenlin (2012) use the direct 
method, the indirect method and the Cline method to calculate the scale of short-term capital, and consider the mean of these three results as the final results; Liu Renwu, Qin Daoai and Liu Hua (2008) uses five different formulas to calculate the scale of short-term international capital flows, and considers a simple weighted average of these five results as the final result. In theory, if the single calculation results all fall on the left or right side of the true value, the simple average of all of the calculation results is not the best results. If one result is on the left side of the true value and the other is on the right side, the simple average of the two results may be the best. Therefore, a simple mathematical approach is not a valid strategy for improving the accuracy of measurement results.

In addition, Zhang Ming (2011), and Mei Li and Junfeng QIU (2012) use the indirect method to estimate the monthly value of short-term international capital flows. Because many of the monthly indicators data are not available, this type of calculation is a relatively rough estimate of short-term international capital flows.

\section{Scale Estimates of Short-Term International Capital Flows}

Balance of Payments (BOP) which reflects a country's international balance of payments is a flow statistics table based on the transactions between residents and non-residents of a country. A BOP table can effectively reflect the balance of payments of a country's total external economic exchange and cross-border capital flow. Generally speaking, all cross-border financial relationships of a country can be reflected in the BOP table. Thus, scale estimates of short-term international capital flows are usually based on the BOP table. Before making formal estimates of short-term international capital flows, we need to clarify three issues: first, short-term and long-term capital exist in which items of the BOP; second, whether there is a logical relationship between the direct and indirect methods; and third, what are the best specific formulas of the direct and indirect methods.

\subsection{Channels of Short-Term Capital Flows}

Much research exists on the channels of short-term capital flows (Such as Liu, Qin, \& Liu, 2008; Qu, 2006; Lin Songli, 2010; Li Huiyong, 2011). This paper does not make an in-depth study of the channels; rather, it conducts a simple comparative analysis to identify the main channel of short-term capital flows and to provide theoretical support for the later choice of calculating indicators of short-term capital flows.

There are four major terms in China's BOP: current account, capital and financial account, reserve assets, and errors and omissions account. Liu Renwu, Qin Daoai and Liu Hua (2008) conducted an in-depth study on the short-term capital flows in the current account, and he found that three sub-projects, i.e. trade items (goods and services), income and current transfers are likely to include short-term capital flows. According to the BOP table, the magnitude of the current account's three sub-projects recorded data indicates that in the case of short-term capital flows, the importance of the trade items is greater than the income items, and the importance of income items is greater than the current transfer items. However, the comparative analysis between Table 1 and Table 2 indicates that most researchers use the current account trade surplus when they estimate the scale of short-term capital flows by direct and indirect methods. The import and export misinvoicing is just one of the ways in which short-term capital flows through trade items, and because of the existence of tax costs and regulation the import and export misinvoicing is impossible to be the main channel of short-term capital flows through trade items (Liu, Qin, \& Liu, 2008). Thus, this study does not select the import and export misinvoicing as an estimating indicator of short-term capital flow.

As for the short-term capital flows in the capital and financial accounts, Liu Renwu, Qin Daoai and Liu Hua (2008) argues that there are five channels, with the most important being foreign direct investment (FDI), short-term external debt, and QFII. Qu Fengjie (2006) believes that the capital from foreign direct investment enterprises in foreign exchange, short-term trade credit, short-term loans, currency and deposits and other assets should be considered as flow channels of short-term international capital flows. Li Huiyong (2011) posits that FDI and foreign short-term liabilities of foreign-invested enterprises and foreign-funded financial institutions are the main flow channels for short-term capital in the capital and financial accounts. According to the magnitude of the recorded data of the capital and financial account in the BOP table, we can find that the item of other investments in the financial account is more important than the direct investment item, and the direct investment item is more important than the item of investments in securities. The capital account will not be included in the analysis of short-term capital flows because its value is too small. On the other hand, the comparative analysis between Table 1 and Table 2 shows that in estimating the scale of short-term capital flows, most researchers use three sub-projects in the financial account, i.e. short-term investments, direct investment, and external debt increment.

In addition to the legitimate channels discussed above, short-term capital can flow through illegal channels. It is generally assumed that such short-term capital flows are reflected in the net errors and omissions of the BOP 
table due to the lack of effective formal indicators for monitoring short-term capital flows through illegal channels. Of course, the changes in the net errors and omissions item are not entirely caused by short-term capital flows coming through illegal channels. These changes can also result from data errors, measurement and rounding errors, unrecorded imports and so on.

\subsection{The logical Relationship between the Direct and Indirect Methods}

It is generally believed that the direct method underestimates measurement results while the indirect method overestimates measurement results (Yang Haizheng and Chen Jinxian, 2000; Zhang Ming, 2011). There is little literature analyzing the relationship between the two methods. As seen from the literature comparison in Table 1 and Table 2, both methods are based on the BOP table. The direct method can be looked on as the addition operation on the base of the net errors and omissions item, while the indirect method is based on foreign exchange reserves for the subtraction operation.

If both of these two methods are based on the BOP table, then there should theoretically be a relationship between the calculation results of the two methods. Assume that SCF1 represents short-term international capital flows calculated using the direct method, SCF2 represents short-term international capital flows calculated using the indirect method, and that the relationship between them can be theoretically shown in the following equation:

$$
S C F 1 \approx S C F 2
$$

We provide a simple proof for equation (1) as follows. We assume that C, D, B, A represent the current account, capital and financial account, reserve assets, and net errors and omissions account respectively in China's BOP table. Then According to the accounting principles of BOP we have:

$$
C+D+A+B=0
$$

Suppose further that short-term capital in the currency account(C) is denoted as CS and long-term capital is denoted as $\mathrm{CL}$, then

$$
C=C S+C L
$$

Short-term capital in the capital and financial account (D) is denoted as DS and long-term capital is denoted as DL, then

$$
D=D S+D L
$$

Short-term capital in net errors and omissions (A) is denoted as AS and the remaining part of A is statistical error and is denoted as $\mathrm{AE}$, then

$$
A=A S+A E
$$

Substituting (3), (4) and (5) into (2) results in:

$$
C S+C L+D S+D L+B+A S+A E=0
$$

Convert equation (6) into the following:

$$
C S+D S+A S+A E=-B-C L-D L
$$

According to the idea of the direct method,

$$
S C F 1=A S+C S+D S
$$

And here AS can be regarded as an adjustment of A. According to the indirect method,

$$
S C F 2=-B-C L-D L
$$

According to (7), (8) and (9), we have:

$$
S C F 1+A E=S C F 2
$$

As AE represents the statistical error in the net errors and omissions item, its mean is zero, i.e.

$$
E(A E)=0
$$

According to (10) and (11), we obtain:

$$
S C F 1 \approx S C F 2
$$

Notably, the BOP table reflects the flow statistics, and the certification process is limited to the situation that indicators used by the two calculation methods are flow indicators. If the indicators used by the indirect method or the direct method involve the stock indicators, the certification process cannot be used.

However, from the perspective of statistical parameter estimation, if we consider the scale of short-term 
international capital flows as a population parameter, the calculation results of both methods are an estimate of this parameter. In theory, the estimations of the same parameter should be similar. Therefore, from the point of view of parameter estimation, the difference between the two calculation results of these two methods should not be small. Otherwise, the only problem lies in the calculation formula selected by researchers.

\subsection{Formula Design for the Direct and Indirect Methods}

According to the analysis above, for the formula design of the direct and indirect methods, the most important thing is to distinguish the short-term capital and long-term capital in the current account and the capital and financial accounts, as well as the short-term capital in the net errors and omissions item in the BOP table. According to the Chinese BOP table and on the base of other literature, we divide the items in the BOP into short-term capital item and long-term capital item, as shown in Table 3.

Table 3. Short-term and long-term capital flow in the BOP

\begin{tabular}{|c|c|}
\hline Long-term item & Short-term item \\
\hline \multicolumn{2}{|l|}{ Workers reward balances (L1) } \\
\hline All levels of government current transfers balances (L 2) & Investment income balances (S 1) \\
\hline Capital account balance (L 3) & Other sectors current transfers balances (S 2) \\
\hline Chinese foreign direct investment balance (L 4) & Money market instruments balances (assets) (S 3) \\
\hline Equity securities balance (assets) (L5) & Equity securities balances (liabilities) (S 4) \\
\hline (medium) Long-term bonds balances (assets) (L6) & Money market instruments balances (liabilities) (S) \\
\hline (medium) Long-term bonds balances (liabilities) (L 7) & Short-term balance of trade credit (assets) (S6) \\
\hline Long-term balances of trade credit (assets) (L8) & Short-term balances of loans (assets) (S7) \\
\hline Long-term balances of loan(assets) (L9) & Short-term balances of other assets (assets) (S8) \\
\hline Currency and deposits balances (assets) (L 10) & Short-term balances of other assets (liabilities) (S9) \\
\hline Long-term balances of other assets (assets) (L11) & Short-term balances of loans (liabilities) (S10) \\
\hline Long-term balances of trade credit (liabilities) (L12) & Currency and deposits balances (liabilities) (S 11) \\
\hline Long-term balances of loan (liabilities) (L13) & Short-term balances of other assets (liabilities) (S12) \\
\hline \multicolumn{2}{|l|}{ Long-term balances of other assets (liabilities) (L14) } \\
\hline \multicolumn{2}{|c|}{ Items need to be adjusted } \\
\hline \multicolumn{2}{|c|}{$\begin{array}{l}\text { The balance of foreign direct investment in China = Actual value of foreign direct investment in China (L15) }+ \text { Short-term capital of foreign } \\
\text { direct investment in China (S13) }\end{array}$} \\
\hline \multicolumn{2}{|c|}{ Goods and services balance $=$ Actual surplus of trade in goods and services $(\mathrm{L} 16)+$ Short-term capital of trade in goods and services(S14) } \\
\hline \multicolumn{2}{|c|}{ Net errors and omissions $=$ The amount of short-term capital flow included in net errors and omissions (S15) + Statistical errors } \\
\hline The amount of change in reserve assets $=$ The increment $\mathrm{c}$ & terpart of foreign exchange reserves(S) +other \\
\hline
\end{tabular}

According to Table 3, the calculation formula for the direct method can be expressed as:

$$
S C F 1=\sum_{i=1}^{15} S_{i}
$$

The meanings of $S_{1}, \ldots, S_{15}$ are shown in Table 1 . The similar formula for the indirect method can be expressed as:

$$
S C F 2=S-\sum_{i=1}^{16} L_{i}
$$

The meaning of $\mathrm{S}$ and $L_{1}, \ldots, L_{16}$ are shown in Table 3.

For the four adjustment items in Table 3, we make the following explanation: First, the adjustment for the item of the balance of foreign direct investment in China is based on the approach of Liu Renwu, Qin Daoai and Liu Hua (2008) and Li Huiyong (2011). Considering that patented technology and machinery account for approximately $20 \%$ of foreign direct investment in China (Li Huiyong, 2011) while short-term capital in foreign direct investment in China is approximatley 30\% (Liu Renwu, Qin Daoai, \& Liu Hua, 2008), we believe that short-term capital accounted for the proportion of total foreign direct investment in China is at an estimated 20\%.

Second, we followed Li Huiyong's (2011) method for the adjustment of the goods and services balance item. We assumed that inflows of speculative capital in the trade account $=$ (net import and export of foreign-invested enterprises / total import and export volume of foreign-invested enterprises - 3\%) ×total imports and exports of 
foreign-invested enterprises, of which $3 \%$ is a reference value given by the average ratio of net import and export to total import and export volume of foreign-invested enterprises in 1997-2004. Considering the ratio of $2.1 \%$ in 2004 and the ratio of $6.8 \%$ in 2005, Li Huiyong (2011) selects the mean of the two ratios (4.47\%) as a reference value. However, it is clear that this approach is defective because it is a simple mean just including two years' values and moreover the difference between these two values is so large because $6.8 \%$ is approximately three times as large as $2.1 \%$.

Third, for the adjustment of net errors and omissions item, we can learn from the approach of Ren Hui (2001). There is no international standard governing what is the normal level of statistical error in the net errors and omissions item. In general, the proportion of the total net errors and omissions to total trade should not be higher than 5\%. As the data in the Chinese BOP table come from several statistics departments, there may be a high level of statistical error. We consider $10 \%$ as the proportion to adjust the net errors and omissions item.

Fourth, to adjust the amount of change in reserve assets, our method is based on the approach of Liu Liya (2008), Lin Songli (2010), Yan Qifa (2010), Zhang Ming (2011), and Li Huiyong (2011). We used the increment of the RMB counterpart of foreign exchange reserves (denoted as $\mathrm{S}$ ) to measure the amount of change in reserve assets which can be looked on as being approximately equal to the amount of change in foreign exchange reserves. In general, the amount of change in foreign exchange reserves should be equal to the sum of the increment of the RMB counterpart of foreign exchange reserves, foreign exchange reserve investment income of last period and assets profit and loss resulting from the change in exchange rates. We use $\mathrm{S}$ to measure the amount of change in reserve assets. Thus, foreign exchange reserve investment income of last period and assets profit and loss resulting from the change in exchange rates are excluded from short-term capital flow.

\subsection{Estimation of Chinese Short-Term International Capital Flows}

According to the design of the calculation formula for the indirect and direct methods, we use annual time series data from 1995-2012 to estimate the annual series of short-term international capital flows by these two methods independently, as shown in Table 4. The calculation results of the annual series based on these two methods are presented in Figure 1.

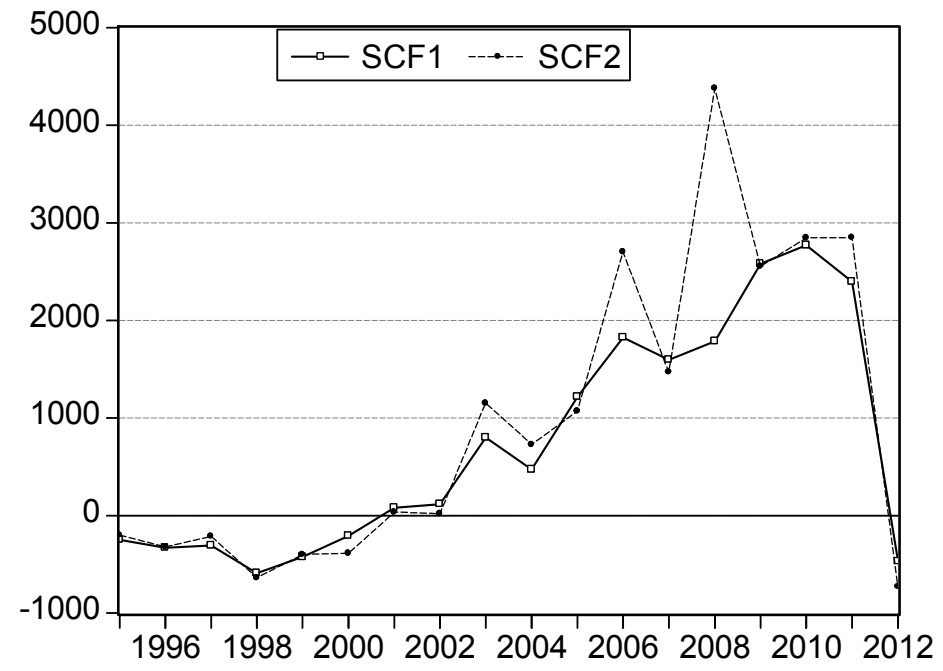

Figure 1. Annual series graph of SCF1 and SCF2 (Unit: 0.1 billion dollars)

Table 4. Calculation results of direct and indirect methods (Unit: 0.1 billion dollars )

\begin{tabular}{ccccccccc}
\hline Time & SCF1 & SCF2 & Time & SCF1 & SCF2 & Time & SCF1 & SCF2 \\
\hline 1995 & -249 & -202 & 2001 & 81 & 34 & 2007 & 1597 & 1470 \\
1996 & -331 & -322 & 2002 & 116 & 17 & 2008 & 1784 & 4377 \\
1997 & -308 & -215 & 2003 & 799 & 1149 & 2009 & 2581 & 2554 \\
1998 & -591 & -640 & 2004 & 471 & 727 & 2010 & 2770 & 2846 \\
1999 & -426 & -400 & 2005 & 1214 & 1069 & 2011 & 2397 & 2847 \\
2000 & -209 & -387 & 2006 & 1823 & 2701 & 2012 & -472 & -732 \\
\hline
\end{tabular}


As seen from the calculation results, short-term capital flows in China appeared mainly to be net outflow before 2001. Within the net outflow, the scale of net short-term capital outflow in 1998 was the largest, at approximately $\$ 60$ billion. From 2002 to 2011, Chinese short-term capital flows showed a net inflow and increased rapidly in scale after 2005. The scale of net inflows reached about $\$ 250$ billion in 2010. What we should note is that the 2012 calculation results showed a net outflow in Chinese short-term capital flows of approximately $\$ 50$ billion.

\section{Test of the Estimation Results}

To test the results of short-term international capital flows, researchers generally compare the results with the real economy. We call this test method the "real event" test method. In addition, we believe that different measurement results should be consistent. This approach is embodied in the so-called "consistency of measurement results" test method. Here the "consistency of measurement results" test method is defined as follows: for the different estimates of one population parameter value, if the results of these estimates are valid, they should have the same directions and similar magnitudes.

\section{1 "Real Event" Test of the Estimation Results}

Since China began to carry out the exchange rate reform in 1997 by implementing the policy of pegging the U.S. dollar's exchange rate, the RMB has enjoyed a relatively stable exchange rate at approximately 8.3. In July 2005, China conducted its first exchange rate reform, implementing a managed floating exchange rate system for the RMB. In June 2010, China conducted its second exchange rate reform, allowing the gradual appreciation of the RMB against the U.S. dollar to accelerate the RMB's internationalization. This reform, however, exacerbated the market's expectations of RMB appreciation.

We divided the estimation results in Table 4 into three stages and used the reality of economy to do the contrast test. The first stage covers 1995 to 2002. China's short-term international capital was mainly earmarked for outflow during this period. Meanwhile, the Asian financial crisis negatively affected market investors. In addition, China's exchange rate reform in 1997 which pegged the U.S. dollar's exchange rate resulted in an overestimation of the RMB in some degree. Two years prior to the outbreak of the Asian financial crisis, China's short-term international capital began to outflow the country. China's net outflow was approximately $\$ 20$ billion in 1995 and 30 billion in 1996. The net outflow scale reached a maximum value in 1998, after which outflow scale was gradually reduced. In 2001 and 2002, the net outflow of short-term capital weakened, and the net flow direction was changed to be inflow.

The second stage of the estimation results covers 2003 to 2005. The short-term international capital in China was inflow during this period, mainly due to an increase in pressure on the depreciation of U.S. dollar after 2003, which forced the market to adjust to the expected appreciation of the RMB exchange rate pegged to the U.S. dollar by the expected depreciation.

The third stage of the estimation results covers 2006 to 2011. Short-term international capitals mainly focused on accelerating the inflow during this time because of the following two main reasons. The first is that the expected appreciation of the RMB was enhanced by the implementation of two exchange rate reforms individually in July 2005 and June 2010. The second is that the interest margin between China and America continued to expand after the U.S. and Europe debt crisis occurred and U.S. imposed a third round of quantitative easing (QE3).

The estimation results in Table 4 indicate that in 2012, China's short-term international capital was earmarked mainly for outflow, including a net outflow of about $\$ 50$ billion. We posit that this net outflow may be associated with three factors. First, China's base currency M2 increased issue more rapidly. And it has exceeded 100 trillion in 2013. Now China has the highest M2-to-GDP ratio in the world. Second, China's asset prices have been pushed up. After 2003, with China's rapid economic development, a variety of asset prices rose rapidly, particularly real estate prices. Third, the scale of government debt is increasing. Some scholars estimate the size of China's local governments, and it will reach approximately \$25 trillion in 2013.

\section{2 "Consistency of Measurement Results" Test}

As for the consistency test of the estimation results using the direct and indirect methods (Table 4), we can see in Figure 1 and Table 4 that the direction of two estimates of the short-term capital flows is consistent. In addition, the size of the magnitude of these two methods' calculation results is largely consistent. The estimation results show a relatively large difference just in 2006 and 2008. This can be attributed to the fact that we adopted S (but did not use the reserve assets increment) to estimate the scale of short-term capital flow. Figure 2 shows the sequence diagram of $\mathrm{S}$ and the reserve assets increment. And it demonstrates that China's $\mathrm{S}$ are significantly higher than the reserve assets increment in 2006 and 2008, which resulted that the measurement results of the 
indirect method are higher than the results of the direct method by using the formula (13) in these two years.

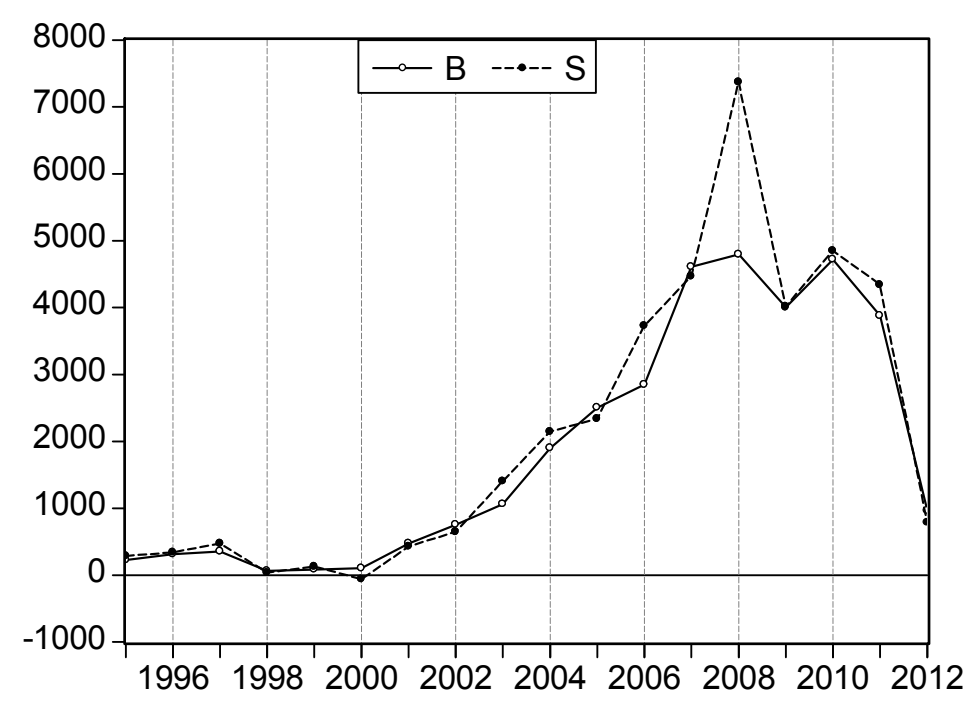

Figure 2. China's S and reserve assets increment (B) sequences' diagram (Unit: 100 million U.S. dollars)

We compared our results to Zhang Ming's (2011) measurement results of six kinds of methods and found that our estimation results were significantly better than Zhang Ming's (2011) on the consistency test. Zhang Ming (2011) estimated a total of 19 years of short-term international capital flows in 1991-2009 in 6 ways. The six-way estimation results only maintained the consistency of the direction of the measurement results in nine years $(1995,1996,1998,1999,2000,2003,2004,2005,2006)$. So for the nineteen estimated values, there are less than $50 \%$ of them satisfying the rule of the consistency of the direction.

\section{Conclusion and Recommendation}

On the basis of Chinese BOP table, this paper demonstrates the relationship between the two common calculation methods of short-term international capital flows and redesigns the calculation formulae of the direct method and indirect method. On this basis, China short-term international capital flows were calculated for 1995 to 2012. We arrived at two main conclusions. First, based on the BOP table, calculation results of direct and indirect methods should be consistent. Second, China's 1995 to 2012 short-term capital flow characteristics can be divided into three stages; from 1995 to 2002, China's short-term international capital was earmarked mainly for outflow; from 2003 to 2005, China's short-term international capital was earmarked mainly for inflow; and from 2006 to 2011, China's short-term international capital was earmarked mainly for accelerating inflow.

We must pay attention to the fact that we measure 2012 short-term international capital flows in net outflows (the size of which is approximately $\$ 50$ billion). We suggest that China's relevant government departments should strengthen their supervision to prevent large-scale short-term capital flows due to the adverse impact on the real economy of the recent short-term capital flows.

In the future, our research of this topic will be developed in the following three aspects. First, on the base of the calculation methods of short-term international capital flows given in this paper, we will further calculate the quarterly data and monthly data of Chinese short-term international capital flows and test the consistency of these different frequency data. Second, we intend to introduce interest rate, exchange rate, house price, GDP and other influential factors to explore the link between short-term international capital flow and macro-economy by applying the VAR model. Third, we plan to analyze the lagging-leading relationship between PMI, GDP and short-term international capital flow by using Kullback-Leibler information method and other methods.

\section{Acknowledgments}

Our research is supported "the Fundamental Research Funds for the Central Universities of China", "the National Key Technology Research and Development Program of the Ministry of Science and Technology of China" and "the Scientific Research Plan Project of the Bureau of Statistics of China". 


\section{References}

Bhagwati, J. (1964). The pure theory of international trade: A survey. The Economic Journal, 74(293). http://dx.doi.org/10.2307/2228112

Bhagwati, J., Krueger, A., \& Wibulswasdi, C. (1974). Capital flight from LDCs: A statistical analysis. In Bhagwati, J. (Ed.), Illegal Transactions In International Trade. North-Holland, Amsterdam. http://dx.doi.org/10.1016/B978-0-444-10581-3.50017-3

Chen, J., \& Xu, Z. (2012). The scale of Chinese short-term international capital flows and its impact on macro economy. Economist, 10, 31-39. Retrieved from http://www.docin.com/p-618491442.html

Chen, X., Yu, C., \& Sun, J. (2007). Empirical Analysis on the influencing factors of international capital flows. Studies of International Finance, 12, 55-60. http://dx.doi.org/10.3969\%2fj.issn.1005-913X.2009.01.042

Chuban, P., Perez-Quiros, G., \& Poper, H. (1996). International capital flows: Do short-term investment and direct investment differ? World Bank Policy Research Working Paper, No.1669.

Claessens, S. (1993). Alternatives forms of external finance: A survey. World Bank Research Observer, 8(1). http://dx.doi.org/10.1093/wbro/8.1.91

Cline, W. R. (1987). Discussion (of Chapter 3). In D. Lessard \& J. Williamson (Eds.), Capital Flight and Third World Debt. Washington D.C.: Institute for International Economics.

Cuddington, \& John. (1986). Capital Flight: Estimates, Issues and Explanations. Princeton Studies in International Finance, 58. Princeton, N.J.: Princeton University, International Finance Section.

Feng, C. (2008). Analyzing the influencing factors of Chinese short-term international capital flows-based on 1994-2007. Finance \& Economics, 6, 32-39. Retrieved from http://www.docin.com/p-786019284.html

International Statistical Information Center of National Bureau of Statistics of China. (2006). Review and prospect of economy development in China and the world from 2005 to 2006. China Statistics Press.

Kant, C. (1996). Foreign Direct Investment and Capital Flight. Princeton Studies in International Finance, No. 80, Princeton, N.J., Princeton University, International Finance Section, March. Retrieved from http://www.princeton.edu/ ies/IES_Studies/S80.pdf

Lan, Z., \& Chen, L. (2008). The estimation of short-term international capital flows and empirical analyzing on $\begin{array}{llll}\text { its influencing factors. Finance and Economy, } & \text { 48-50. }\end{array}$ http://dx.doi.org/10.3969\%2fj.issn.1007-0753.2007.02.029

Li, C. (2003). The risk of short-term capital flows and Chinese capital account liberalization. Changbai Journal, 1, 66-69. Retrieved from http://wenku.baidu.com/link?url=WPWePGWCHVeZK-EqfB0dKxngYpCjtRQqP0N37djgGbACjxbRaiw6p Hv7PyJ_O_Bcp6EDWIPU5bLoL_HDCj19gP5C9fMUZkjwf4GQ6qqmCQO

Li, H. (2011). What is the true size of "hot money"?-Estimating the size of "hot money" based on the balance of payments. Macroeconomic in-depth report of Shenyin \& Wanguo Securities Co., Ltd. Retrieved from http://www.doc88.com/p-579886116143.html

Li, X. (2000). The theory and reality of the Chinese capital flight. Management World, 4, 21-29. Retrieved from $\mathrm{http}: / / \mathrm{www} \cdot \mathrm{doc} 88 . \mathrm{com} / \mathrm{p}-6601638893488 . \mathrm{html}$

Lin, S. (2010). Calculation of Chinese hot money scale over the years and forecast in the future ten years. Macroeconomic in-depth report of Guoxin Securities Co., Ltd. Retrieved from http://finance.sina.com.cn/stock/stockptd/20100402/09297682909.shtml

Liu, L. (2008). Does hot money promote the stock market and the housing market to rise? Evidence from China. Journal of Financial Research, 10, 48-70. http://dx.doi.org/10.1109\%2fTSMCB.2009.2036931

Liu, R., Qin, D., \& Liu, H. (2008). The regulation on the international short-term capital flows. Social Sciences Documentation Publishing House.

Mei, L., \& Qiu., J. (2012). Speculative capital inflows, adaptive expectations, and the optimal Renminbi appreciation policy. China Economic Review, 6, 6-28. http://dx.doi.org/10.1016/j.chieco.2012.05.008

Michaelson, L. (2010). Hot money flow in China: a Look at the rapport between international capital flows and the business cycle. The Conference Board China Center, August 9.

Morgan Guaranty Trust Company. (1986). LDC Capital Flight. World Financial Markets, March, 12-15. 
Qu, F. (2006). The statement and Statistics Empirical Analysis of Chinese short-term capital flows. Review of Economic Research, 40, 14-21. Retrieved from http://wenku.baidu.com/link?url=TKVMePm0J7PGDqYfejBivdBDqcAiFmiljqg6jOnhyLTULYR4tNY7mq VOqiQdfEcvgPEiVyarjuTZnfVzksc0VOVijDemNF3rh1P18VVW5j

Ren, H. (2001). The calculation and countermeasures analyzing of Chinese capital flight. Economic Research Journal, $11, \quad 69-75 . \quad$ Retrieved from http://www.erj.cn/UploadFiles/\%E4\%B8\%AD\%E5\%9B\%BD\%E8\%B5\%84\%E6\%9C\%AC\%E5\%A4\%96 \%Е9\%80\%83\%Е7\%9A\%84\%Е8\%A7\%84\%Е6\%A8\%A1\%Е6\%B5\%8B\%Е7\%AE\%97\%Е5\%92\%8C\%Е5 $\% \mathrm{AF} \% \mathrm{~B} 9 \% \mathrm{E} 7 \% \mathrm{AD} \% 96 \% \mathrm{E} 5 \% 88 \% 86 \% \mathrm{E} 6 \% 9 \mathrm{E} \% 90$.pdf

Rodrik, D., \& Velasco, A. (1999). Short-term capital flows. National Bureau of Economic Research Working Paper, No. 7346. Abstract retrieved from http://www.nber.org/papers/w7364

Schneider, B. (2003). Measuring capital flight: Estimates and interpretations. Overseas Development Institute

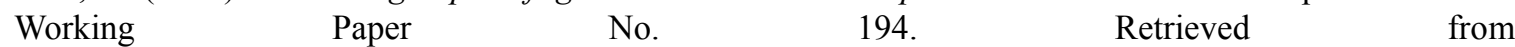
http://r4d.dfid.gov.uk/PDF/Outputs/Mis_SPC/R8007CapitalFlightReport.pdf

Song, W. (1999). The research on the problem of capital flight in China from 1987 to 1997. Economic Research Journal, 5, 14-20. Retrieved from http://neri.org.cn/document/2012040210461678161.pdf

State Administration of Foreign Exchange. (2005). Analysis of financial vulnerability: Construction of early warning system of Chinese cross-border capital flows. China Commerce and Trade Press.

State Administration of Foreign Exchange. (2011). A report on China's across-boarder flows of funds in 2011. China Financial Publishing House. http://dx.doi.org/10.1134\%2fS0018143911050134

Tang, X., \& Liang, M. (2007). If hot money exists in the Trade Surplus of China, how much? Journal of Financial Research, 9, 1-19. Retrieved from http://blog.sina.com.cn/s/blog_49f5fed3010094af.html

Wang, S., \& He, F. (2007). Short-term international capital flows in China: the current situation, flow path and influential factors. The Journal of World Economy, 7, 12-19. http://dx.doi.org/10.3969\%2fj.issn.1002-9621.2007.07.002

Wang, X. (2005). Changes in short-term capital flows in China since the 1990s. Studies of International Finance, 12, 25-32. Retrieved from http://wenku.baidu.com/link?url=CzKppJOW5nnHtmbLkCAoXIDut6ONumjmgDdR-44zdaqFm7nuV_eO A3GOblqYVA3xTDujN6f0ApXJGLhRpMnyIYnWxVKn925Dq9BBL8G7Pyq

Wang, Y. (2010). Chinese hot money: Analyzing aspects and abnormal behavior. In Z. Zhang \& F. He (Eds.), World Economy And China In Post-Crisis Era. China: China Society of World Economics.

World Bank. (1985). World Development Report. Washington D.C.

Xiu, J., \& Zhang, M. (2002). Calculation of the Chinese capital flight and analysis of its influential factors. World Economic Papers, 1, 37-44. http://dx.doi.org/10.3969\%2fj.issn.0488-6364.2002.01.004

Xu, G. (2007). Capital flight in China: Analysis of monthly data from 1999 to 2006. Discussion Paper of China Center For Economic Research of Peking University, No. C2007005. Retrieved from http://219.219.191.244:1980/upload/tongji/sld/7839-1.pdf

Yalta, A. Y., \& Yalta, A. T. (2012). Does financial liberalization decrease capital flight? A panel causality analysis. International Review of Economics and Finance, 22(1), 92-100. http://dx.doi.org/10.1016/j.iref.2011.09.003

Yan, Q. (2010). Situation and review of Chinese abnormal capital outflows from 2000. International Trade and Commerce, 12, 1-13. Retrieved from http://www.cf40.org.cn/plus/view.php?aid=3264

Yang, H., \& Chen, J. (2000). Chinese capital flight: estimation and international comparison. The Journal of World Economy, 1, 21-29.

Yang, S., \& Liu, Z. (2000). Capital flight and China's realistic choice. Journal of Financial Research, 2, 73-79.

Yin, Y., \& Tao, H. (2005). The scale of hot money and its impact. Finance \& Economics, 6, 31-137. http://dx.doi.org/10.3969\%2fj.issn.1000-8306.2005.06.021

Yu, S., \& Zhang, W. (2008). Measuring the variability of non-FDI capital inflows. Journal of Southeast University (Philosophy and Social Science Edition), 5, 13-21. Retrieved from http://www.doc88.com/p-999520609978.html 
Zhang, B. (2010). The expectation of RMB appreciation and its impact on short-term capital flows. International Finance, 4, 55-60. Retrieved from http://www.cf40.org.cn/plus/view.php?aid=2559

Zhang, M. (2008). The current hot money's scale and channel flowing into China. International Finance, 7, 5964. Retrieved from http://news1.jrj.com.cn/news/main/Ver0701/images/sp/20086251185336533.pdf

Zhang, M. (2011). Chinese short-term international capital flows: calculation base on different methods and caliber. The Journal of World Economy, 2, 39-56. Retrieved from http://www.cf40.org.cn/uploads/qingnianluntan/20110221 zhangming.pd

Zhang, M., \& Xu, Y. (2008). Full-caliber measurement of Chinese current hot money scale. Journal of Contemporary Asia-Pacific Studies, 4, 126-142. Abstract retrieved from http://www.cnki.com.cn/Article/CJFDTotal-DDYT200804012.htm

Zhang, Y., \& Shen, X. (2008). An empirical study on the relationship among RMB appreciation, rise of the stock and hot money inflows. Journal of Financial Research, 11, 27-36. Retrieved from http://www.doc88.com/p-771870280616.html

\section{Copyrights}

Copyright for this article is retained by the author(s), with first publication rights granted to the journal.

This is an open-access article distributed under the terms and conditions of the Creative Commons Attribution license (http://creativecommons.org/licenses/by/3.0/). 